\title{
Prosocial People Take Better Care of Their Own Future Well-Being
}

\author{
Sergio Da Silva1*, Raul Matsushita², Mateus De Carvalho ${ }^{3}$ \\ ${ }^{1}$ Department of Economics, Federal University of Santa Catarina, Florianopolis, Brazil \\ ${ }^{2}$ Department of Statistics, University of Brasilia, Brasilia, Brazil \\ ${ }^{3}$ Department of Economics, University of Birmingham, Birmingham, UK \\ Email: *professorsergiodasilva@gmail.com
}

Received 28 November 2015; accepted 12 December 2015; published 18 December 2015

Copyright (C) 2015 by authors and OALib.

This work is licensed under the Creative Commons Attribution International License (CC BY). http://creativecommons.org/licenses/by/4.0/

\section{(c) (†) Open Access}

\section{Abstract}

There is neuroscientific evidence that people consider future versions of themselves as other people. As a result, intertemporal choice should refer to the interaction between multiple selves. We combine this notion of multiple selves in delay discounting with the approach for otherregarding preferences known as Social Value Orientation. The Social Value Orientation is a psychologically richer framework that generalizes the economic assumption of narrow self-interest. People are assumed to vary in their motivations toward resource allocation between them and the others. When making such allocation decisions they may still be individualistic, but can also be competitive, prosocial, or even altruistic. We apply an experimental measure of impatience to a sample of 437 undergraduates, measure their Social Value Orientation, and collect selected demographic variables: gender, age, handedness, parenthood, religiousness, and current emotional state. We find prosocial participants to be more patient. Those who care for the others in the present also take better care of themselves in the future. We also find a participant's age and handedness to matter for his or her Social Value Orientation.

\section{Keywords}

Other-Regarding Preferences, Social Value Orientation, Multiple Selves, Intertemporal Choice, Impatience

Subject Areas: Behavioral Economics

\section{Introduction}

Decision-making involves a trade-off between the present and the future. Neurologically, this intertemporal

${ }^{*}$ Corresponding author. 
choice made by one's current and future selves is substantially the same as that involving a trade-off between oneself's current payoff and that of other people. Indeed, brain areas involved with imagining oneself in the future ("prospection") happen to be the same as those involved with the mentalization of other people (known as "theory of mind") [1]. A single core network (medial prefrontal, medial-temporal, medial and lateral parietal, lateral prefrontal and occipital cortices) underlies a number of cognitive domains previously seen as distinct, including prospection and theory of mind [2].

Here, we explore the experimental implications of this result. We apply questionnaires to a sample of 437 undergraduates to assess their prospection and theory of mind. We focus on the time preference dimension of prospection [3], and consider the aspect of theory of mind related to social preferences [4]. We also collect selected demographic variables of the participants: gender, age, handedness, parenthood, religiousness, and current emotional state.

To measure the magnitude of the concern people have for the others, we take a "slider measure" of Social Value Orientation [4] [5] to be discussed in details in the next section. The Social Value Orientation (SVO) is a psychologically richer, other-regarding preferences framework that generalizes the economic assumption of narrow self-interest. People are assumed to vary in their motivations toward resource allocation between them and the others. When making such allocation decisions they may still be individualistic, but can also be competitive, prosocial, or even altruistic. Individualistic people maximize their self-payoff; prosocial people maximize the joint payoff or minimize the difference between payoffs; competitive people maximize the positive difference between self-payoff and the other's payoff; and altruistic people maximize the other's payoff.

These are primary motivations, but secondary motivations can also be tracked: sadistic, masochistic, sadomasochistic and martyr. Sadistic people minimize the other's payoff; the masochistic people minimize the selfpayoff; the sadomasochistic people minimize the joint payoff or minimize the difference between payoffs; and the martyr people maximize the negative difference between the other's payoff and self-payoff [5].

Because self-interest is a particular SVO (individualistic orientation), considering a spectrum of different orientations does not challenge rational choice theory, but rather extends the individualistic postulate to consider a richer psychology [4]. For example, questionnaire responses can be filtered to allow for the assumption of transitivity to hold for the social preferences reported [4].

In our sample, other-regarding preferences prove to be related to a participant's time delay attitude. We find prosocial participants to be more patient. Those who care for the others in the present also take better care of themselves in the future. We also find a participant's age and handedness to matter for his or her social preferences.

In literature, age affects one's behavior. For example, age is correlated with risk-taking [6]. Unlike adults, kids are risk-lovers [7]. There are not significant neurological differences between 25 years old and 75 years old. However, there is an inability to accurately perceive risks between the ages of 10 and the mid-20s because hormonal factors trigger a need to impress peers by reckless behavior. Sensation-seekers tend to have higher levels of testosterone than others [8], and tend to have lower levels of monoamine oxidase, an enzyme that regulates serotonin, which in turn regulates mood. Thus, it is not unreasonable to speculate that all these hormonal differences can be linked to one's other-regarding preferences.

As for the handedness polymorphism, approximately 10 to 13 percent of any population is left-handed. Such a proportion has remained constant over a long period of 30,000 years, thus suggesting an evolutionary role for left-handedness. The left-handed occupy the extremes of the distributions of a number of neurological characteristics. Disproportionately, many left-handed people have IQs greater than 140, and are associated with musical talent and athleticism. The downside is that left-handedness is also linked to epilepsy, down syndrome, autism and mental retardation. For a review, see Ref. [9]. It is then reasonable to assume that the neurological differences associated with handedness can be linked to one's other-regarding preferences.

The remaining demographic characteristics considered in this study-gender, parenthood, religiousness, and current emotional state-proved not to be related to SVO in our sample. For a discussion of why these characteristics might matter, see Ref. [10].

The next section presents the measures employed to treat data and the details of the experiment. Then, we show the results in Section 3. Section 4 concludes the study.

\section{Materials and Methods}

The SVO Slider Measure is a choice task as in Figure 1 [4] [5]. Each item is a resource allocation choice over a 

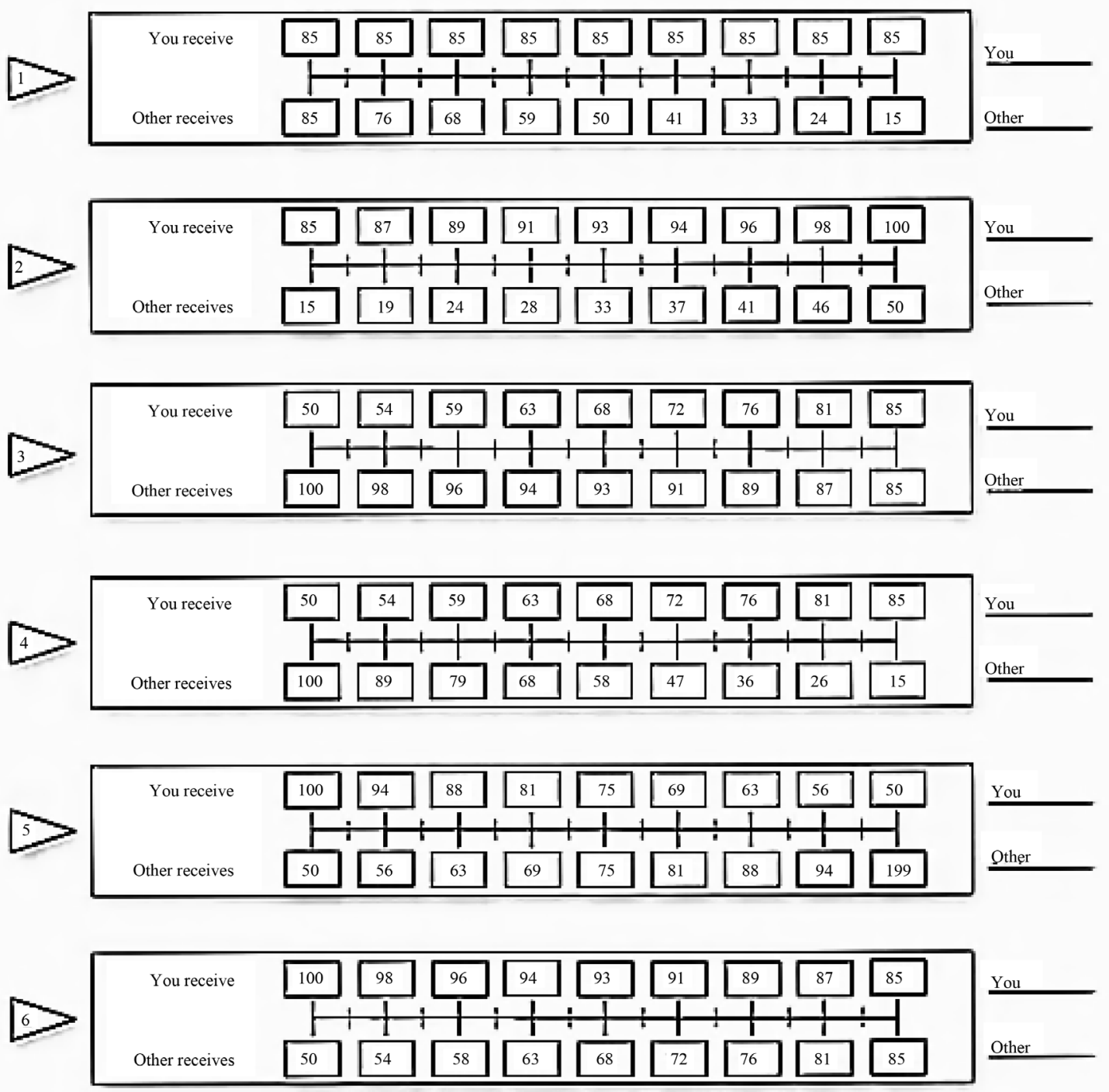

Figure 1. Test showing SVO Slider items. Source: Ref. [4].

continuum of joint payoffs. One respondent indicates his allocation choice by marking a line at the point that defines his most-preferred joint distribution. Then, he writes to the right of the item the corresponding payoffs resulting from his choice. Though this is redundant, it serves to verify that the respondent understood the choice task and the resulting allocations. The mean allocation for self $\bar{A}_{s}$ and the mean allocation for the other $\bar{A}_{o}$ are computed from all six items in Figure 1. Then, 50 is subtracted from $\bar{A}_{s}$ and $\bar{A}_{o}$ to shift the base of the resulting angle to the center of the circle $(50,50)$. The index of a respondent's $\mathrm{SVO}$ is then:

$$
\mathrm{SVO}^{\circ}=\arctan \frac{\bar{A}_{0}-50}{\bar{A}_{s}-50} .
$$

Depending on the value generated from the test in Figure 1, the SVO allocations define the other-regarding preferences as follows:

Altruism: $\mathrm{SVO}^{\circ}>57.15^{\circ}$

Prosociality: $22.45^{\circ}<\mathrm{SVO}^{\circ}<57.15^{\circ}$

Individualism: $-12.04^{\circ}<\mathrm{SVO}^{\circ}<22.45^{\circ}$

Competitiveness: $\mathrm{SVO}^{\circ}<-12.04^{\circ}$ 
We consider only the primary SVO allocations, as in Figure 2, because these ended up relevant for the answers we received from the questionnaires. These results are presented in the next section.

To track one participant's impatience, we consider the experimental measure suggested in Ref. [3]. Table 1 shows the time preference decision sheet presented to each participant. The list in Table 1 aims to elicit one

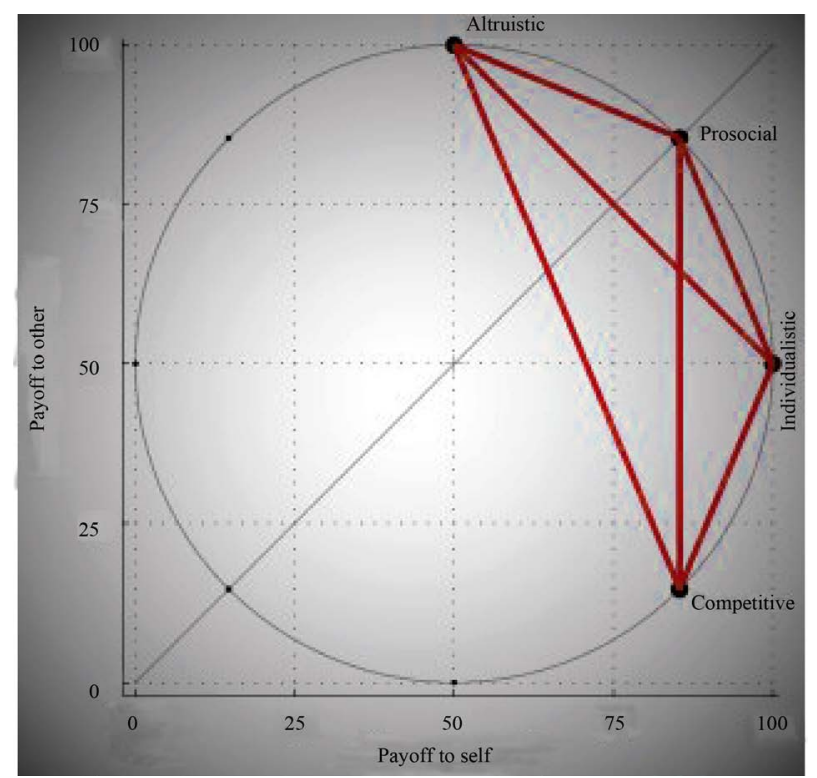

Figure 2. The self-other allocation plane for the primary Social Value Orientations. Source: Ref. [4].

Table 1. Time preference decision sheet.

\begin{tabular}{|c|c|c|c|c|c|}
\hline & Amount today & & or & & Amount in 3 weeks \\
\hline 1 & $\$ 5.10$ today & O & or & O & $\$ 5.10$ in 3 weeks \\
\hline 2 & $\$ 5.10$ today & O & or & $\bigcirc$ & $\$ 5.30$ in 3 weeks \\
\hline 3 & $\$ 5.10$ today & ○ & or & ○ & $\$ 5.50$ in 3 weeks \\
\hline 4 & $\$ 5.10$ today & ○ & or & ○ & $\$ 5.70$ in 3 weeks \\
\hline 5 & $\$ 5.10$ today & ○ & or & ○ & $\$ 5.90$ in 3 weeks \\
\hline 6 & $\$ 5.10$ today & ○ & or & $\bigcirc$ & $\$ 6.10$ in 3 weeks \\
\hline 7 & $\$ 5.10$ today & O & or & O & $\$ 6.30$ in 3 weeks \\
\hline 8 & $\$ 5.10$ today & ○ & or & ○ & $\$ 6.50$ in 3 weeks \\
\hline 9 & $\$ 5.10$ today & O & or & O & $\$ 6.70$ in 3 weeks \\
\hline 10 & $\$ 5.10$ today & O & or & $\bigcirc$ & $\$ 6.90$ in 3 weeks \\
\hline 11 & $\$ 5.10$ today & ○ & or & ○ & $\$ 7.10$ in 3 weeks \\
\hline 12 & $\$ 5.10$ today & O & or & ○ & $\$ 7.30$ in 3 weeks \\
\hline 13 & $\$ 5.10$ today & O & or & $\bigcirc$ & $\$ 7.50$ in 3 weeks \\
\hline 14 & $\$ 5.10$ today & O & or & O & $\$ 7.70$ in 3 weeks \\
\hline 15 & $\$ 5.10$ today & ○ & or & ○ & $\$ 7.90$ in 3 weeks \\
\hline 16 & $\$ 5.10$ today & O & or & $\bigcirc$ & $\$ 8.10$ in 3 weeks \\
\hline 17 & $\$ 5.10$ today & O & or & ○ & $\$ 8.30$ in 3 weeks \\
\hline 18 & $\$ 5.10$ today & ○ & or & ○ & $\$ 8.50$ in 3 weeks \\
\hline 19 & $\$ 5.10$ today & O & or & O & $\$ 8.70$ in 3 weeks \\
\hline 20 & $\$ 5.10$ today & 0 & or & O & $\$ 8.90$ in 3 weeks \\
\hline
\end{tabular}

Source: Adapted from Ref. [3]. 
participant's attitude toward delay (impatience) by letting him or her choose between sure payoffs at two different points in time. The early payoff remained fixed at $\$ 5.10$ Brazilian reais, and the later payoff was increased monotonically along the list, starting with the payoff at the earlier time point (\$5.10). From one participant’s list, we calculate the "future equivalent" of the fixed payoff at the earlier point in time as the midpoint between the two later payoffs, where the participant switches from the earlier to the later payment [3]. The greater the future equivalent, the stronger delay aversion, which means more impatience.

We also collected data for each participant's gender (male or female), age, handedness (right-handed or left-handed), whether he or she has children and lives with them, whether he or she believes in God, and his or her current emotional state. As for the latter, a continuous affect scale was presented, ranging from "very anxious" and "moderately anxious" to "emotionless," "moderately excited" and "very excited" [10].

Undergraduates from the three largest universities located in Florianopolis, southern Brazil, were shown the questionnaires (as in Figure 1 and Table 1) to assess their SVO and impatience respectively. Their demographic characteristics were also collected through an extra questionnaire. The universities were UFSC (Federal University of Santa Catarina), UDESC (State University of Santa Catarina) and CESUSC (Higher Education Colleges of Santa Catarina). The students came from economics, business administration, civil engineering, law, accounting and international relations. A total of 437 undergraduates participated. The questionnaires were applied in classrooms by the experimenter (MDC) with the consent of teachers. From the total, 41 respondents failed to complete at least one out of the three questionnaires. Thus, we proceeded to the analysis of results with a smaller sample of 392 participants.

Monetary incentives were offered to the participants. In each classroom, one student was randomly drawn and the choices he or she made for the SVO and impatience tests were fulfilled. For the SVO, cash was instantly paid after the tests were completed for both the lucky participant and an unknown passerby outside the classroom. As for the impatience test, $\$ 5.10$ in cash was instantly paid for the lucky participant if he or she chose the amount today (as in Table 1). If not, the experimenter paid the teacher the amount chosen, and the lucky student was then repaid three weeks later.

\section{Results}

Most respondents were either prosocial (50 percent) or individualistic (46 percent), and only one participant was altruistic. The remaining respondents were competitive.

From the data collected, we considered the Akaike information criterion for variable selection and adjusted the linear regression:

$$
\mathrm{SVO}^{\circ}=29.57-2 \mathrm{FE}+0.36 \mathrm{~A}-4.32 \mathrm{H},
$$

where $\mathrm{FE}$ stands for future equivalent, $\mathrm{A}$, for age, and $\mathrm{H}$ is a dummy (left-handed: $\mathrm{H}=0$; right-handed: $\mathrm{H}=1$ ). Thus, the $\mathrm{SVO}^{\circ}$ is lower, the greater the future equivalent (or the stronger the delay aversion or the greater the impatience). Moreover, the $\mathrm{SVO}^{\circ}$ is positively related to age: the lower the $\mathrm{SVO}^{\circ}$, the lower the age. Also, the $\mathrm{SVO}^{\circ}$ is lower for the right-handed. Perhaps, the left-handed tend to be relatively more prosocial. The other demographic variables failed to be selected.

Table 2 shows the $R$-squares are low, but $\operatorname{Pr}>|t|$ for the variables future equivalent, age and handedness. Thus, despite the low predicting power, the estimated model is still useful for detecting behavioral tendencies. Considering the average future equivalent (6.5) and the average age (23) for the right-handed (who was the majority: only 12 percent was left-handed) one can find $\mathrm{SVO}^{\circ}=20.53$ using Equation (3). From Equation (2), this means the average participant was individualistic. This is not so surprising for university students. The low average age alone explains the fact that the average undergraduate in the sample was individualistic. Indeed, if, for example, one considers the average age of the Brazilian population in 2015, which is 32, and keeps the same values for the other variables as above, Equation (3) now produces an $\mathrm{SVO}^{\circ}=23.77$, which falls within the range of prosociality. Thus, considering Equation (3), populations of older countries are expected to generate an even higher average $\mathrm{SVO}^{\circ}$. This finding agrees with the literature, where most studies using the general population find a prosocial average $\mathrm{SVO}^{\circ}$ [4] [11] [12]. However, in studies considering students, the average $\mathrm{SVO}^{\circ}$ tends to be more individualistic [13], a result also in line with ours.

\section{Conclusion}

Because intertemporal choice is made between multiple selves, we speculate one's attitude toward the others 
Table 2. Social value orientation, impatience, age and handedness.

\begin{tabular}{|c|c|c|c|c|c|}
\hline \multicolumn{6}{|c|}{ Analysis of variance } \\
\hline Source & $\mathrm{DF}$ & Sum of squares & Mean square & $F$-value & Pr. $>F$ \\
\hline Model & 3 & 4046 & 1348 & 6.07 & 0.0005 \\
\hline Error & 388 & 86,241 & 222 & & \\
\hline \multirow[t]{3}{*}{ Corrected total } & 391 & 90,288 & & & \\
\hline & & & & $R$-square & 0.0448 \\
\hline & & & & Adj. $R$-sq. & 0.0374 \\
\hline \multicolumn{6}{|c|}{ Parameter estimates } \\
\hline Variable & $\mathrm{DF}$ & Parameter estimate & Standard error & $t$-value & Pr. $>|t|$ \\
\hline Intercept & 1 & 29.57 & 6.15 & 4.81 & $<0.0001$ \\
\hline Future equivalent & 1 & -2 & 0.68 & -2.96 & 0.0033 \\
\hline Age & 1 & 0.36 & 0.15 & 2.41 & 0.0165 \\
\hline Handedness & 1 & -4.31 & 2.24 & -1.93 & 0.0549 \\
\hline
\end{tabular}

predicts one's future attitude toward oneself. This is confirmed in an experiment with undergraduates. The prosocial are also the more patient. Because patience is associated with wiser economic decisions such as saving money, we conclude that prosocial people take better care of their own future well-being. Incidentally, we also find a role for age and handedness in explaining other-regarding preferences. The older tend to adopt more prosocial attitudes than the younger, which is something most people would intuitively agree. Unexpectedly, we also find that those who are left-handed are relatively less individualistic.

\section{References}

[1] Jamison, J. and Wegener, J. (2010) Multiple Selves in Intertemporal Choice. Journal of Economic Psychology, 31, 832-839. http://dx.doi.org/10.1016/j.joep.2010.03.004

[2] Spreng, R.N., Mar, R.A. and Kim, A.S.N. (2009) The Common Neural Basis of Autobiographical Memory, Prospection, Navigation, Theory of Mind and the Default Mode: A Quantitative Meta-Analysis. Journal of Cognitive Neuroscience, 21, 489-510. http://dx.doi.org/10.1162/jocn.2008.21029

[3] Sutter, M., Kocher, M.G., Glatzle-Ruetzler, D. and Trautmann, S.T. (2013) Impatience and Uncertainty: Experimental Decisions Predict Adolescents’ Field Behavior. American Economic Review, 103, 510-531. http://dx.doi.org/10.1257/aer.103.1.510

[4] Murphy, R.O., Ackermann, K.A. and Handgraaf, M.J.J. (2011) Measuring Social Value Orientation. Judgment and Decision Making, 6, 771-781. http://dx.doi.org/10.2139/ssrn.1804189

[5] Murphy, R.O. and Ackermann, K.A. (2011) A Review of Measurement Methods for Social Preferences. ETH Zurich Chair of Decision Theory and Behavioral Game Theory, Working Paper.

[6] Llaurens, V., Raymond, M. and Faurie, C. (2009) Why Are Some People Left-Handed? An Evolutionary Perspective. Philosophical Transactions of the Real Society of London B, 364, 881-894. http://dx.doi.org/10.1098/rstb.2008.0235

[7] Moreira, B., Matsushita, R. and Da Silva, S. (2010) Risk Seeking Behavior of Preschool Children in a Gambling Task. Journal of Economic Psychology, 31, 794-801. http://dx.doi.org/10.1016/j.joep.2010.03.005

[8] Campbell, B.C., Dreber, A., Apicella, C.L., Eisenberg, D.T., Gray, P.B., Little, A.C., Garcia, J.R., Zamore, R.S. and Lum, J.K. (2010) Testosterone Exposure, Dopaminergic Reward, and Sensation-Seeking in Young Men. Physiology \& Behavior, 99, 451-456. http://dx.doi.org/10.1016/j.physbeh.2009.12.011

[9] Dohmen, T.J., Falk, A., Huffman, D., Sunde, U., Schupp, J. and Wagner, G.G. (2005) Individual Risk Attitudes: New Evidence from a Large, Representative, Experimentally Validated Survey. IZA Discussion Papers No. 1730.

[10] Da Silva, S., Baldo, D. and Matsushita, R. (2013) Biological Correlates of the Allais Paradox. Applied Economics, 45, 555-568. http://dx.doi.org/10.1080/00036846.2011.607133

[11] Liebrand, W.B.G. (1984) The Effect of Social Motives, Communication and Group Size on Behaviour in an N-Person Multi-Stage Mixed-Motive Game. European Journal of Social Psychology, 14, 239-264. http://dx.doi.org/10.1002/ejsp.2420140302

[12] Van Lange, P.A.M., De Bruin, E.M.N., Otten, W. and Joireman, J.A. (1997) Development of Prosocial, Individualistic, 
and Competitive Orientations: Theory and Preliminary Evidence. Journal of Personality and Social Psychology, 73, 733-746. http://dx.doi.org/10.1037/0022-3514.73.4.733

[13] Liebrand, W.B.G. and McClintock, C.G. (1988) The Ring Measure of Social Values: A Computerized Procedure for Assessing Individual Differences in Information Processing and Social Value Orientation. European Journal of Personality, 2, 217-230. http://dx.doi.org/10.1002/per.2410020304 